\title{
Factors Affecting Treatment Interruption among TB Patients in Lagos Nigeria: Is There Any Need for Treatment Supporters?
}

\author{
Olusola Adedeji Adejumo ${ }^{1 *}$, Olusoji James Daniel ${ }^{2}$, Andrew Folarin Otesanya ${ }^{3}$, \\ Temitope Ashipa ${ }^{4}$, Esther Ngozi Adejumo5, Husseine A. Abdur-Razzaq ${ }^{6}$ \\ ${ }^{1}$ Department of Community Health and Primary Health Care, Lagos State University Teaching Hospital, Ikeja, \\ Lagos, Nigeria \\ ${ }^{2}$ Department of Community Medicine and Primary Care, Olabisi Onabanjo University Teaching Hospital, \\ Sagamu, Ogun State, Nigeria \\ ${ }^{3}$ Medical Services Department Central Bank of Nigeria, Lagos, Nigeria \\ ${ }^{4}$ Department of Community Medicine, Babcock University Teaching Hospital, Ilishan-Remo, Ogun State, Nigeria \\ ${ }^{5}$ Department of Medical Laboratory Science, Babcock University, Ilisan-Remo, Ogun State, Nigeria \\ ${ }^{6}$ Lagos State TB and Leprosy Control Programme, Lagos State Ministry of Health, Alausa, Ikeja, Lagos, Nigeria \\ Email: "drolus adejumo@yahoo.com, "oluadejumo75@gmail.com
}

Received 29 April 2016; accepted 20 June 2016; published 23 June 2016

Copyright (C) 2016 by authors and Scientific Research Publishing Inc.

This work is licensed under the Creative Commons Attribution International License (CC BY).

http://creativecommons.org/licenses/by/4.0/

c) (7) Open Access

\begin{abstract}
Background: This study assessed treatment interruption of tuberculosis (TB) patients managed by treatment supporters and health care workers and other predictors of treatment interruption. Methods: A descriptive cross-sectional study was conducted. Four hundred and seventy new smear positive TB patients above 14 years of age were consecutively recruited between 0ctober 1 and December 312012 from 34 (23 public and 11 private) directly observed treatment short course (DOTS) facilities that offered TB treatment and microscopy services. They were followed up till treatment was completed. Logistic regression was used to assess the predictors of treatment interruption. Results: A significantly higher proportion of smokers $(58.6 \%$ vs $38.3 \%$, p = $0.030)$, patients supervised by treatment supporters $(44.4 \%$ vs $34.7 \%, p=0.032)$, patients not counselled before initiation of treatment $(55.6 \%$ vs $38.2 \%, p=0.041)$, patients managed at private DOTS facilities $(50 \%$ vs $36.3 \%, p=0.010)$ and $\mathrm{TB} / \mathrm{HIV}$ co-infected patients $(54.2 \%$ vs $38.6 \%, \mathrm{p}=$ 0.038) had treatment interruption. Predictors of treatment interruption were supervision by treatment supporters, smoking, lack of pre-treatment counselling and TB/HIV co-infection. Conclusion: A higher proportion of patients supervised by treatment supporters had treatment interruption than those supervised by health care workers. There may be a need to review the concept of treatment supervision by treatment supporters in Lagos state Nigeria.
\end{abstract}

"Corresponding author.

How to cite this paper: Adejumo, O.A., Daniel, O.J., Otesanya, A.F., Ashipa, T., Adejumo, E.N. and Abdur-Razzaq, H.A. (2016) Factors Affecting Treatment Interruption among TB Patients in Lagos Nigeria: Is There Any Need for Treatment Supporters? International Journal of Clinical Medicine, 7, 389-398. http://dx.doi.org/10.4236/ijcm.2016.76042 
Keywords

Treatment Supporter, Treatment Interruption, Tuberculosis, DOTS, Nigeria

\section{Introduction}

The National tuberculosis and leprosy control programme (NTBLCP) commenced the implementation of the directly observed treatment short course (DOTS) in Nigeria over two decades ago [1]. However, despite the availability of DOTS facilities in all local government areas (districts) in the country, Nigeria is far from achieving the global targets. Tuberculosis (TB) burden in Nigeria is estimated to be 318 per 100,000 [2] and less than twenty percent of the estimated TB prevalence was notified in 2013 [3]. In addition, the World Health Organization (WHO) estimated that 2.9\% (2.1\% - 4.0\%) and 14\% (10\% - 19\%) of new and retreated TB cases respectively had multi-drug resistant tuberculosis (MDR-TB) [3].

Although there is efficacious chemotherapy for TB treatment, therapy requires greater than ninety percent compliance to facilitate treatment success and reduce the emergence of MDR-TB [4]-[6]. Treatment interruption is a major obstacle in TB control [7]. Reasons for treatment interruption are complex and include patients' characteristics and income, the socio-cultural context, chronic nature of TB and patients' relationship with health care workers [8] [9].

Different methods such as monitoring system, pill counts, fixed dose combinations and supervised therapy were used previously to ensure patients' adherence to TB treatment [8] [10] [11]. Under the DOTS programme, TB treatment was initially supervised daily by health care workers during the first two months of treatment. However for many TB patients in most TB high burden countries including Nigeria, treatment interruption was a challenge because of financial accessibility to TB services as majority live some distance from the DOTS facilities and are often too weak to make frequent visits to access care [12].

To address this issue, "patient centered treatment" which allowed TB patients to determine whether treatment was supervised at the health facility by health care workers or at home by any treatment supporter of their choice was introduced [13]. The NTBLCP guidelines stipulated that treatment supporter can be a relation or someone (volunteer) close to the patient's home and has been trained to provide support for TB patients on treatment [14]. A study from Nigeria showed that few of the community volunteers served as treatment supporter and the community TB care in the country was not effective [15]. Studies from West and East Africa, Asia and South America have shown that the use of family members as treatment supporters was effective [16]-[20]. However, the effectiveness of treatment supporters depends on the type and age of treatment supporter, mode of selection, quality of training, proximity to patients, employment and educational status [21] [22].

Since the introduction of patient centered treatment in Nigeria in 2007, no study has assessed the role of treatment supporters in reducing treatment interruption among TB patients. This study assessed treatment interruption of patients managed by treatment supporters and health care workers and other factors associated with treatment interruption among TB patients managed in Lagos Nigeria.

\section{Methods}

\subsection{Study Design}

This study was a descriptive cross sectional study that assessed factors associated with treatment interruption of TB patients in Lagos Nigeria.

\subsection{Study Background and TB Control in Lagos Nigeria}

The study was done in Lagos state, the commercial nerve centre of Nigeria with an estimated population of 21 million [23]. TB control was coordinated by the Lagos State TB and leprosy control programme (LSTBLCP). The DOTS management of TB started in 2003 with the public sector and in 2008 the systematic engagement of the private sector began. TB diagnosis and treatment is free in the state. Duration of TB treatment was eight months consisting of two months intensive phase and six months continuation phase. Rifampicin, Isoniazid, Pyrazina- 
mide and Ethambutol as fixed dose combination were given during the intensive phase while Ethambutol and Isonizid were given during the continuation phase as fixed dose combination. Usually patients were counselled on drug usage, possible side effects and consequences of treatment interruption before commencement of treatment. In order to reduce treatment interruption and loss to follow up, patients diagnosed of TB were managed at DOTS facility closest to their residents regardless of where TB diagnosis was made. Sputum microscopy, clinical assessment and drug intake were used to monitor TB treatment. Sputum microscopy was done at the $2^{\text {nd }}, 5^{\text {th }}$ and $7^{\text {th }}$ month of treatment for smear positive patients, clinical assessment included weight monitoring and assessment of patient's records for regularity of drug intake [14].

All presumptive TB clients were offered HIV test at no cost. Determine (determine HIV-1/2 Alere Determine $^{\mathrm{TM}}$, Japan 2012) and Uni-Gold ${ }^{\mathrm{TM}}$ (Trinity Biotech PLC, Wicklow, Ireland 2013) were used in parallel algorithm. STAT-PAK ${ }^{\circledR}$ was used as tie breaker for discordant results. TB/HIV co-infected patients were usually referred to anti retroviral therapy (ART) clinic for assessment and commencement of anti retroviral (ARV) drugs. In most cases TB drugs were commenced first before ARV drugs. TB/HIV co-infected patients were offered co-trimoxazole in addition to anti-TB drugs.

TB focal persons were in charge of each DOTS facility and records generated from each DOTS facility were sent to the local government TB supervisor who collates the records of DOTS facilities in the LGA (district) and send to the State TB coordinator who in turn forwards the state records to the national TB coordinator [14].

\subsection{Population and Sample}

Four hundred and seventy new smear positive TB patients were recruited from 34 DOTS facilities (23 from public and 11 private) out of the sample frame of 130 DOTS facilities provided by the Lagos State TB control officer between October 1 and December 31 2012. Selection criteria includes: provision of treatment and microscopy services and involvement in DOTS programme at least two years prior to data collection. Details of the sample size calculation were earlier published [24].

\subsection{Study Procedure}

A structured questionnaire was administered on all TB patients after recruitment into the study. Information on socio demographic data, clinical signs and symptoms and their duration, nature of the health facility first visited, whether treatment was supervised by treatment supporter or by health care worker at the DOTS facilities, whether counselling was done by health care worker before initiation of treatment were obtained. The weight, sputum and HIV test results were copied from patients' facility treatment card before commencement of patients on the 8 months anti TB regimen.

Drug use was directly observed daily during the intensive phase by the health care workers at the selected DOTS facilities for patients supervised by them, but during the continuation phase; patients were given monthly appointment. For patients not supervised by the health care workers, drugs were given to their treatment supporters to cover for two weeks. Treatment supporters were expected to supervise and record patients' treatment at home on a card. Empty drug blisters and the card (where drug intake was recorded) were presented to the health care workers at DOTS facilities before drug refill. The health care workers updated patients' health facility records from the card presented by the treatment supporters and days when patients interrupted treatment were recorded. Pattern of drug intake of patients supervised by the health care workers were also documented. Patients were followed up till completion of treatment.

\subsection{Definition of Outcome Variable}

In this study any patient who failed to collect drugs for two consecutive days during the intensive phase or two weeks after the expected date during the continuation phase were regarded as having interrupted treatment according to the NTBLCP guidelines [14].

\subsection{Data Analysis}

The Statistical Package of Social Sciences (SPSS) IBM version 19 was used for data analysis. Percentages, mean and standard deviation of numerical variables were determined. Chi squared test was used to compare categorical variables. Binary logistic regression was used to assess the predictors of treatment interruption. All (independent) 
variable that were significant $(\mathrm{p}<0.05)$ on bivariate analysis were entered at once (enter method) at the beginning to assess their predictive ability. Omnibus test of model coefficients value less than 0.05 and the Hosmer-Lemeshow goodness of fit test value greater than 0.05 were used to assess if the model was good quality. Confidence interval was set at $95 \%$ for all statistical tests. Statistical test was considered significant if $\mathrm{p}<0.05$.

\subsection{Ethical Approval}

Ethical approval was obtained from the Health Research and Ethical Committee of the Lagos State University Teaching Hospital. Written informed consent was obtained from TB patients before recruitment into the study.

\section{Results}

Of the 470 smear positive patients recruited for the study, 358 (23.8\%) and 112 (76.2\%) were from the private and public DOTS facilities respectively. Mean age of patients was $33.0 \pm 11.6$. About $60 \%$ (280) were males. 254 (54.1\%) had secondary school education, while 417 (88.7\%) earned less than 125 USD monthly. About 12\% (56) and 6\% (29) drank alcohol and smoked cigarette respectively. TB/HIV patients constituted $10.2 \%$ of the patients recruited as shown in Table 1. Figure 1 shows that 186 (39.6\%) of the patients recruited interrupted treatment.

A significantly higher proportion of smokers $(58.6 \%$ vs $38.3 \%, \mathrm{p}=0.030)$, patients supervised by treatment supporters ( $44.4 \%$ vs $34.7 \%, p=0.032)$, patients not counselled before initiation of treatment $(55.6 \%$ vs $38.2 \%$, $\mathrm{p}=0.041)$, patients managed at the private DOTS facilities (50\% vs $36.3 \%, \mathrm{p}=0.010)$ and TB/HIV co-infected patients $(54.2 \%$ vs $38.6 \%, \mathrm{p}=0.038)$ had treatment interruption than non-smokers, patients supervised by health

Table 1. Socio demographic characteristics of TB patients.

\begin{tabular}{|c|c|c|}
\hline \multicolumn{2}{|c|}{ Variable } & \multirow{2}{*}{$\begin{array}{c}\text { Frequency } n=470(\%) \\
114(24.3)\end{array}$} \\
\hline \multirow{5}{*}{ Age group (years) } & $15-24$ & \\
\hline & $25-34$ & $170(36.2)$ \\
\hline & $35-44$ & $105(22.3)$ \\
\hline & $\geq 45$ & $81(17.2)$ \\
\hline & Mean \pm SD & $33.0 \pm 11.6$ \\
\hline \multirow{2}{*}{ Gender } & Male & $280(59.6)$ \\
\hline & Female & $190(40.4)$ \\
\hline \multirow{4}{*}{ Educational status } & No formal education & $29(6.1)$ \\
\hline & Primary education & 84 (17.9) \\
\hline & Secondary & $254(54.1)$ \\
\hline & Post secondary & 103 (21.9) \\
\hline \multirow{2}{*}{ Income } & $<50,000$ naira & 417 (88.7) \\
\hline & $\geq 50,000$ naira & $53(11.3)$ \\
\hline \multirow{2}{*}{ Drink Alcohol } & Yes & $56(11.9)$ \\
\hline & No & $414(88.1)$ \\
\hline \multirow{2}{*}{ Smoke cigarette } & Yes & $29(6.2)$ \\
\hline & No & 441 (93.8) \\
\hline \multirow{3}{*}{ HIV status } & Positive & $48(10.2)$ \\
\hline & Negative & 394 (83.8) \\
\hline & Not done & $28(6.0)$ \\
\hline \multirow{2}{*}{ Type of DOTS facility } & Public & $358(76.2)$ \\
\hline & Private & 112 (23.8) \\
\hline
\end{tabular}

NB: ${ }^{\#}=$ Includes single, divorced, separated and widowed. 
workers, patients counselled before treatment, patients managed at the public DOTS facilities and HIV negative patients respectively (Table 2).

Binary logistic regression was used to assess the ability of the explanatory variables such as cigarette smoking, who supervised treatment, pre-treatment counselling, type of DOTS facility where treatment was administered and HIV status to predict treatment interruption. The full model containing all predictors was statistically significant $\times 2(6, \mathrm{~N}=442)=36.48, \mathrm{p}<0.001$. The model as a whole explained between $23.2 \%$ (cox and snell $\mathrm{R}$ squared) and $34.5 \%$ (Nagalkerke R squared) of the variance in treatment interruption and correctly classified $78.7 \%$ of cases. Lack of pre-treatment counseling made the strongest unique contribution (OR 5.338, 95\% CI 2.520 - 11.308) to explaining treatment interruption (dependent variable). Other predictors of treatment interrup-

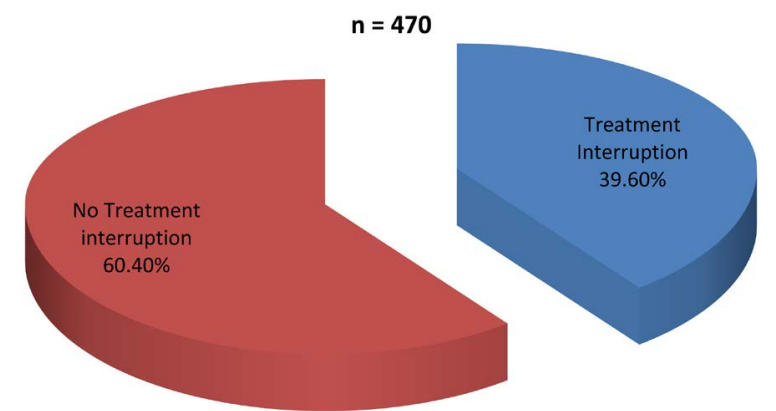

Figure 1. Prevalence of treatment interruption among TB patients.

Table 2. Factors associated with patient interruption among TB patients.

\begin{tabular}{|c|c|c|c|c|c|}
\hline \multicolumn{2}{|c|}{ Variable } & \multicolumn{4}{|c|}{ Patient interruption } \\
\hline & & Yes $n=284(\%)$ & No $n=186(\%)$ & $\times 2$ & $\mathbf{p}$ \\
\hline \multirow{2}{*}{ Age group (years) } & $<35$ & $168(59.2)$ & $116(40.8)$ & 0.484 & 0.486 \\
\hline & $\geq 35$ & $116(62.4)$ & $70(37.6)$ & & \\
\hline \multirow{2}{*}{ Gender } & Male & $168(60.0)$ & $112(40.0)$ & 0.052 & 0.819 \\
\hline & Female & $116(61.1)$ & 74 (38.9) & & \\
\hline \multirow{2}{*}{ Educational status } & Less than secondary & 70 (61.9) & $43(38.1)$ & 0.144 & 0.704 \\
\hline & Not below secondary & 214 (59.9) & $143(40.1)$ & & \\
\hline \multirow{2}{*}{ Income } & $<125$ USD & 256 (61.4) & $161(38.6)$ & 1.732 & 0.188 \\
\hline & $\geq 125$ USD & $27(51.90)$ & $25(48.1)$ & & \\
\hline \multirow{2}{*}{ Alcohol intake } & Yes & $36(64.3)$ & $20(35.7)$ & 0.396 & 0.529 \\
\hline & No & 248 (59.9) & $166(40.1)$ & & \\
\hline \multirow{2}{*}{ Smoke cigarette } & Yes & $12(41.4)$ & $17(58.6)$ & 4.689 & 0.030 \\
\hline & No & $272(61.7)$ & 169 (38.3) & & \\
\hline \multirow{2}{*}{ Treatment supervision } & Treatment supporter & $130(55.6)$ & $104(44.4)$ & 4.622 & 0.032 \\
\hline & Health care worker & $154(65.3)$ & $82(34.7)$ & & \\
\hline \multirow{2}{*}{ Pre treatment counselling } & Done & $268(61.8)$ & $166(38.2)$ & 4.164 & 0.041 \\
\hline & Not done & $16(44.4)$ & $20(55.6)$ & & \\
\hline \multirow{2}{*}{ Type of DOTS facility } & Public & $228(63.7)$ & $130(36.3)$ & 6.683 & 0.010 \\
\hline & Private & $56(50.0)$ & $56(50.0)$ & & \\
\hline \multirow{3}{*}{ HIV status } & Positive & $22(45.8)$ & $26(54.2)$ & 4.322 & 0.038 \\
\hline & Negative & 242 (61.4) & 152 (38.6) & & \\
\hline & Not done $\mathrm{e}^{\#}$ & $20(71.4)$ & 8 (28.6) & & \\
\hline
\end{tabular}

NB: ${ }^{\#}=$ Not part of the analysis. 
tion were smoking (OR 2.043, 95\% CI 1.257 - 3.321), treatment supervision by treatment supporters (OR 2.043, 95\% CI 1.257 - 3.321) and TB/HIV co-infected patients (OR 2.058, 95\% CI 1.057 - 4.006) (Table 3).

\section{Discussion}

\subsection{Prevalence of Treatment Interruption}

In this study, about $40 \%$ of patients had TB treatment interruption, this is low compared with findings from Nigeria and elsewhere [25]-[27]. The reason for this finding is unknown. However, recruitment of patients from many DOTS facilities may be responsible for this finding. Many studies from Nigeria assessed the prevalence of TB treatment interruption in a DOTS treatment facility [25]-[27].

\subsection{Factors Associated with Treatment Interruption}

Adherence to treatment regimen is pivotal to TB control, and the involvement of the community is important in this regard especially where culturally appropriate support is available near a patient's home [28]. Treatment supporters have evolved to assist TB control programs in low-income countries and those with high TB prevalence [22]. Anecdotal evidence however shows that the quality of support provided by treatment supporters varies significantly [22]. In our study, patients managed by treatment supporters were twice likely to have treatment interruption than patients managed by health care workers. This is contrary to the findings from Tanzania and Ghana which reported better treatment outcome and lower treatment interruption among patients supervised by treatment supporters. However, the closer the treatment supporter live to the patient, the better the treatment adherence [16]-[18].

Although the NTBLCP guidelines stipulates that treatment supporters must live close to the patients and be trained by the health care worker [14], there was no mechanism in place to verify patients claim whenever a treatment supporter was presented. In addition, the health care workers often do not follow the NTBLCP recommended standard operating procedures for the engagement of treatment supporters. A potential challenge to the effectiveness of treatment supporters is quality control especially when observation is performed by a non-medical supporter outside a health facility [16] [22]. It has also been suggested that treatment supporters should not be seen as a "quick fix" for failing TB control programs. For better effectiveness of treatment supporters, there must be a well organized and functional health system [22].

Counselling for TB adherence is a process of improving patients' knowledge about TB, enhancing their belief to complete treatment and developing skills to overcome negative family and community environments [29]. It often strengthens patients to overcome problems that may jeopardize adherence [29]. Studies have shown that counselling enhances patients' adherence to TB treatment [30]-[32]. In this study, pre-treatment counselling was associated with treatment interruption. Patients who reported that they were not counselled before the commencement of TB treatment were five times likely to interrupt treatment than those who reported they were counselled before treatment. Similar finding was obtained in a randomized controlled intervention trial. Counselling improved patients' knowledge about TB and minimized treatment interruption [33], although earlier studies from Pakistan and elsewhere showed that counselling had no significant impact on treatment interruption even with monetary incentive to patients [29] [34]. Other authors have however suggested that the success of any counselling program is dependent not only on the qualification and competence of health care workers but also their attitudes towards patients, their desire to improve patients' treatment outcome, and the type of intervention [30] [31] [35] [36].

Table 3. Predictors of treatment interruption.

\begin{tabular}{cccccc}
\hline Variable & B & Wald & p & OR & 95\% CI \\
Smokers & 0.963 & 4.771 & 0.029 & 2.620 & 2.043 \\
Treatment supporter & 0.714 & 8.304 & 0.004 & $1.257-3.321$ \\
No pre-treatment counselling & 1.675 & 19.121 & $<0.001$ & 5.338 & 2.058 \\
TB/HIV co-infection & 0.722 & 4.506 & 0.034 & $1.057-4.006$ \\
Treatment at private DOTS facility & 0.405 & 2.111 & 0.146 & 1.500 \\
\hline
\end{tabular}

Odds ratio adjusted. 
Cigarette smoking has been shown to be associated with TB infection, disease and death [37]-[39]. It can also affect treatment outcomes and studies have shown that smoking was associated with unsuccessful treatment outcomes, default and relapse [40]-[42]. In this study, smokers had over 2 fold risk of treatment interruption than non-smokers. This may be because majority of smokers (96.6\%) in this study were males and men have demonstrated poor adherence to TB treatment [43]. This may be because of economic reasons because traditionally, men are expected to provide for the family and time taken out for medical visit may mean less income. In addition they may need to take permission from their work place which may not be possible with paid employment [44].

Patient with TB/HIV co-infection in addition to TB care need to get HIV care and may interrupt TB treatment more frequently than those who are HIV negative. This may be due to the cost of attending two clinics especially if both clinics are not located within the same hospital [45]. In this study TB/HIV co-infected patients were twice likely to interrupt treatment than TB/HIV negative patients. Several studies have reported factors associated with treatment interruption of TB/HIV co-infected patients. Believe in efficacy of TB treatment, pill burden, side effects of drugs, failure of health workers to counsel patients of the potential side effects, HIV related stigma and discrimination and lack of disclosure were reported in studies from Nigeria, Ethiopia and Nepal as factors affecting adherence in TB/HIV co-infected patients [45]-[51].

\subsection{Limitation of the Study}

No enquiry was made in this study to ascertain whether treatment supporters actually lived close to TB patients, truly observed the patients' treatment or personally filled the treatment supporters' card. This study assessed factors associated with treatment interruption under programmatic condition.

\section{Conclusion}

A higher proportion of patients supervised by treatment supporters had treatment interruption than those supervised by health care workers. There is a need for health care workers at DOTS facilities to adhere strictly to the guidelines for selection of treatment supporters and take time to counsel TB patients before they are commenced on treatment. The need for further research to assess the effectiveness of treatment supporters in Lagos State Nigeria cannot be over emphasized.

\section{Acknowledgements}

The authors wish to acknowledge all the Lagos State TB control officer, TB focal persons, LGA TB supervisors and the Lagos State Ministry of Health for their support. The research was self funded and findings and conclusion are those of the authors.

\section{Competing Interests}

Authors have declared that no competing interests exist.

\section{Authors Contribution}

AAO conceived the study, involved with data collection, data analysis and discussion. OJD wrote the methodology and was involved in the writing process, AFO was involved in drafting the manuscript and revision. ENA and HAA were involved in literature search and proof reading the manuscript.

\section{References}

[1] Federal Ministry of Health (2009) National Tuberculosis and Leprosy Control Programme. Nigeria 2008 NTBLCP Annual Report. http://www.ntbltc.org/reports/Annual\%20Report\%202008\%20NTBLCP.pdf

[2] World Health Organization (2014) First National TB Prevalence Survey 2012 Nigeria. http://www.who.int/tb/publications/NigeriaReport_WEB_NEW.pdf

[3] World Health Organization (2016) Global Tuberculosis Report 2014. WHO, Geneva http://apps.who.int/iris/bitstream/10665/137094/1/9789241564809 eng.pdf

[4] Awofeso, N. (2008) Antituberculosis Medication Side Effects Constitute a Major Factor for Poor Adherence for Tu- 
berculosis Treatment. Bulletin of the World Health Organization, 86.

[5] Uzochukwu, B.S., Onwujekwe, O.E., Onoka, A.C., Okoli, C., Uguru, N.P. and Chukwuogo, O.I. (2009) Determinants of Non-Adherence to Subsidized Anti-Retroviral Treatment in Southeast Nigeria. Health Policy Plan, 24, 189-196. http://dx.doi.org/10.1093/heapol/czp006

[6] van den Boogaard, J., Boeree, M.J., Kibiki, G.S. and Aarnoutse, R.E. (2011) The Complexity of the Adherence-Response Relationship in Tuberculosis Treatment: Why Are We Still in the Dark and How Can We Get Out? Tropical Medicine and International Health, 16, 693-698. http://dx.doi.org/10.1111/j.1365-3156.2011.02755.x

[7] World Health Organization (2003) Adherence to Long Term Therapies: Evidence for Action. World Health Organization, Geneva.

[8] Sumartojo, E. (1993) When Tuberculosis Treatment Fails: A Social Behavorial Account of Patient Adherence. American Review of Respiratory Disease, 147, 1311-1320. http://dx.doi.org/10.1164/ajrccm/147.5.1311

[9] Hill, P.C., Stevens, W., Hill, S., et al. (2005) Risk Factors for Defaulting from Tuberculosis Treatment: A Prospective Cohort Study of 301 Cases in the Gambia. International Journal of Tuberculosis and Lung Disease, 9, 1349-1354.

[10] Kochi, A. (1991) The Global Tuberculosis Situation and the New Control Strategy of the World Health Organization. Tubercle, 72, 1-6. http://dx.doi.org/10.1016/0041-3879(91)90017-M

[11] Grange, M.J. and Festenstein, F. (1993) The Human Dimension of Tuberculosis Control. Tubercle and Lung Disease, 74, 219-222. http://dx.doi.org/10.1016/0962-8479(93)90046-Z

[12] Federal Ministry of Health Department of Public Health (2012) Guidelines for Community Tuberculosis Care in Nigeria National Tuberculosis and Leprosy. FMOH.

[13] Egwaga, S., Range, N., Lwilla, F., et al. (2008) Assessment of Patient Preference in Allocation and Observation of Anti-Tuberculosis Medication in Three Districts in Tanzania. Patient Prefer Adherence, 2, 1-6.

[14] Federal Ministry of Health (2012) National Tuberculosis and Leprosy Control Programme. Models for Training of General Health Care Workers on Tuberculosis Control. 5th Edition, Sounasprints, Abuja, 8-51.

[15] Adejumo, A.O., Azuogu, B., Okorie, O., Lawal, O.M., Onazi, O.J., Gidado, M., Daniel, O.J., Okeibunor, J.C., Klinkenberg, E. and Mitchell, E.M.H. (2016) Community Referral for Presumptive TB in Nigeria: A Comparison of Four Models of Active Case Finding. BMC Public Health, 16, 177. http://dx.doi.org/10.1186/s12889-016-2769-7

[16] Mkopi, A., Range, N., Lwilla, F., Egwaga, S., Schulze, A. and van Leth, F. (2012) Adherence to Tuberculosis Therapy among Patients Receiving Home-Based Directly Observed Treatment: Evidence from the United Republic of Tanzania. PLoS ONE, 7, e51828. http://dx.doi.org/10.1371/journal.pone.0051828

[17] Egwaga, S., Mkopi, A., Range, N., et al. (2009) Patient Centred Tuberculosis Treatment Delivery under Programmatic Conditions in Tanzania: A Cohort Study. BMC Medicine, 7, 80. http://dx.doi.org/10.1186/1741-7015-7-80

[18] Danso, E., Addo, I.Y. and Ampomah, I.G. (2015) Patients’ Compliance with Tuberculosis Medication in Ghana: Evidence from a Periurban Community. Advances in Public Health, 2015, Article ID: 948487.

[19] Newell, J.N., Baral, S.C., Pande, S.B., Bam, D.S. and Malla, P. (2006) Family Member DOTS and Community DOTS for Tuberculosis Control in Nepal: Cluster-Randomised Controlled Trial. The Lancet, 367, 903-909. http://dx.doi.org/10.1016/S0140-6736(06)68380-3

[20] Maciel, E.L., Guidoni, L.M., Brioshi, A.P., et al. (2010) Household Members and Health Care Workers as Supervisors of Tuberculosis Treatment. Revista de Saúde Pública, 44, 339-343. http://dx.doi.org/10.1590/S0034-89102010000200015

[21] Zwarenstein, M., Schoeman, J.H., Vundule, C., Lombard, C. and Tatley, M. (2000) A Randomized Controlled Trial of Lay Health Workers as Direct Observers for Treatment of Tuberculosis. International Journal of Tuberculosis and Lung Disease, 4, 550-554.

[22] Dick, J., Murray, E. and Botha, E. (2005) The Effectiveness of TB DOTS Supporters in South Africa. Operations Research Results. Published for the U.S. Agency for International Development (USAID) by the Quality Assurance Project (QAP), Bethesda.

[23] Lagos State Government. Population of Lagos State. www.lagosstate.gov.ng

[24] Adejumo, A.O., Daniel, O.J., Adejumo, E.N., Oluwole, E.O. and Olumuyiwa, O.O. (2015) Treatment Outcomes of Tuberculosis Patients Managed at the Public and Private DOTS facilities in Lagos Nigeria. International Journal of Tropical Disease \& Health, 10, 1-9. http://dx.doi.org/10.9734/IJTDH/2015/19933

[25] Erhabor, G.E., Aghanwa, H.S., Yusuph, M., Adebayo, M.A., Arogundade, F.A. and Omidiora, A. (2000) Factors Influencing Compliance in Patients with Tuberculosis on Directly Observed Therapy at Ile-Ife, Nigeria. The East African Medical Journal, 77, 235-239.

[26] Anyaike, C., Musa, O.I., Babatunde, O.A., Bolarinwa, O.A., Durowade, K.A. and Ajayi, O.S. (2013) Adherence to Tuberculosis Therapy in Unilorin Teaching Hospital, Ilorin, North-Central Nigeria. International Journal of Science, 
Environment and Technology, 2, 1441-1461.

[27] Amuha, M.G., Kutyabami, P., Kitutu, F.E., Odoi-Adome, R. and Kalyango, J.N. (2009) Non-Adherence to Anti-TB Drugs among TB/HIV Co-Infected Patients in Mbarara Hospital Uganda: Prevalence and Associated Factors. African Health Sciences, 9, S8-S15.

[28] Friedman, I. (2003) Community Based Health Workers in the South African Health Review 2002. Health Systems Trust, Durban.

[29] Liefooghe, R., Suetens, C., Meulemans, H., Moran, M.B. and De Muynck, A. (1999) A Randomised Trial of the Impact of Counselling on Treatment Adherence of Tuberculosis Patients in Sialkot, Pakistan. International Journal of Tuberculosis and Lung Disease, 3, 1073-1080.

[30] Lee, S., Khan, O.F., Seo, J.H., Kim, D.Y., Park, K.H., Jung, S., Chung, E.K. and Jang, H.C. (2013) Impact of Physician's Education on Adherence to Tuberculosis Treatment for Patients of Low Socioeconomic Status in Bangladesh. Chonnam Medical Journal, 49, 27-30. http://dx.doi.org/10.4068/cmj.2013.49.1.27

[31] M’Imunya, J.M., Kredo, T. and Volmink, J. (2012) Patient Education and Counselling for Promoting Adherence to Treatment for Tuberculosis. Cochrane Database Systematic Reviews, No. 5, Article No. CD006591. http://dx.doi.org/10.1002/14651858.CD006591.pub2

[32] Atkins, S., Lewin, S., Ringsberg, K.C. and Thorson, A. (2012) Towards an Empowerment Approach in Tuberculosis Treatment in Cape Town, South Africa: A Qualitative Analysis of Programmatic Change. Global Health Action, 5, 14385. http://dx.doi.org/10.3402/gha.v5i0.14385

[33] Thiam, S., LeFevre, A.M., Hane, F., Ndiaye, A., Ba, F., Fielding, K.L., et al. (2007) Effectiveness of a Strategy to Improve Adherence to Tuberculosis Treatment in a Resource-Poor Setting: A Cluster Randomized Controlled Trial. JAMA, 297, 380-386. http://dx.doi.org/10.1001/jama.297.4.380

[34] Morisky, D.E., Malotte, C.K., Choi, P., Davidson, P., Rigler, S., Sugland, B. and Langer, M. (1990) A Patient Education Program to Improve Adherence Rates with Antituberculosis Drug Regimens. Health Education \& Behavior, 17, 253-267. http://dx.doi.org/10.1177/109019819001700303

[35] Hane, F., Thiam, S., Fall, A.S., Vidal, L., Diop, A.H., Ndir, M. and Lienhardt, C. (2007) Identifying Barriers to Effective Tuberculosis Control in Senegal: An Anthropological Approach. International Journal of Tuberculosis and Lung Disease, 11, 539-543.

[36] Mohammed, A.Y. and Adem, M.K. (2014) Treatment Adherence among Tuberculosis and Human Immuno Deficiency Virus Coinfected Patients in Ginnir Referral Hospital. American Journal of Public Health Research, 2, $239-243$. http://dx.doi.org/10.12691/ajphr-2-6-4

[37] Bates, M.N., Khalakdina, A., Pai, M., Chang, L., Lessa, F. and Smith, K.R. (2007) Risk of Tuberculosis from Exposure to Tobacco Smoke: A Systematic Review and Meta-Analysis. Archives of Internal Medicine, 167, 335-342. http://dx.doi.org/10.1001/archinte.167.4.335

[38] Lin, H.H., Ezzati, M. and Murray, M. (2007) Tobacco Smoke, Indoor Air Pollution and Tuberculosis: A Systematic Review and Meta-Analysis. PLoS Medicine, 4, e20. http://dx.doi.org/10.1371/journal.pmed.0040020

[39] Slama, K., Chiang, C.Y., Enarson, D.A., et al. (2007) Tobacco and Tuberculosis: A Qualitative Systematic Review and Meta-Analysis. International Journal of Tuberculosis and Lung Disease, 11, 1049-1061.

[40] Khan, A.H., Israr, M., Khan, A., Aftab, R.A. and Khan, T.M. (2015) Smoking on Treatment Outcomes among Tuberculosis Patients. The American Journal of the Medical Sciences, 349, 505-509. http://dx.doi.org/10.1097/MAJ.0000000000000473

[41] Thomas, A., Gopi, P.G., Santha, T., et al. (2005) Predictors of Relapse among Pulmonary Tuberculosis Patients Treated in a DOTS Programme in South India. International Journal of Tuberculosis and Lung Disease, 9, 556-561.

[42] Tachfouti, N., Nejjari, C., Benjelloun, M.C., Berraho, M., Elfakir, S., El Rhazi, K. and Slama, K. (2011) Association between Smoking Status, Other Factors and Tuberculosis Treatment Failure in Morocco. International Journal of Tuberculosis and Lung Disease, 15, 838-843. http://dx.doi.org/10.5588/ijtld.10.0437

[43] Lavigne, M., Rocher, I., Steensma, C. and Brassard, P. (2006) The Impact of Smoking on Adherence to Treatment for Latent Tuberculosis Infection. BMC Public Health, 6, 66. http://dx.doi.org/10.1186/1471-2458-6-66

[44] O’Boyle, S.J., Power, J.J., Ibrahim, M.Y. and Watson, J.P. (2002) Factors Affecting Patient Compliance with AntiTuberculosis Chemotherapy Using the Directly Observed Treatment, Short-Course Strategy (DOTS). International Journal of Tuberculosis and Lung Disease, 6, 307-312.

[45] Tadesse, T., Demissie, M., Berhane, Y., Kebede, Y. and Abebe, M. (2013) Long Distance Travelling and Financial Burdens Discourage Tuberculosis DOTs Treatment Initiation and Compliance in Ethiopia: A Qualitative Study. BMC Public Health, 13, 424. http://dx.doi.org/10.1186/1471-2458-13-424

[46] Munro, S.A., Lewin, S.A., Smith, H.J., Engel, M.E., Fretheim, A. and Volmink, J. (2007) Patient Adherence to Tuber- 
culosis Treatment: A Systematic Review of Qualitative Research. PLoS Medicine, 4, e238. http://dx.doi.org/10.1371/journal.pmed.0040238

[47] Wares, D.F., Singh, S., Acharya, A.K. and Dangi, R. (2003) Non-Adherence to Tuberculosis Treatment in the Eastern Tarai of Nepal. International Journal of Tuberculosis and Lung Disease, 7, 327-335.

[48] Shargie, E.B. and Lindtjørn, B. (2007) Determinants of Treatment Adherence among Smear Positive Pulmonary Tuberculosis Patients in Southern Ethiopia. PLoS Medicine, 4, e37. http://dx.doi.org/10.1371/journal.pmed.0040037

[49] Sagbakken, M., Frich, J.C. and Bjune, G. (2008) Barriers and Enablers in the Management of Tuberculosis Treatment in Addis-Ababa, Ethiopia: A Qualitative Study. BMC Public Health, 8, 11. http://dx.doi.org/10.1186/1471-2458-8-11

[50] Gebremariam, M.K., Bjune, G.A. and Frich, J.C. (2010) Barriers and Facilitators of Adherence to TB Treatment in Patients on Concomitant TB and HIV Treatment: A Qualitative Study. BMC Public Health, 10, 651.

[51] Daniel, O.J. and Alausa, O.K. (2006) Treatment Outcome of TB/HIV Positive and TB/HIV Negative Patients on Directly Observed Treatment, Short Course (DOTS) in Sagamu, Nigeria. Nigerian Journal of Medicine, 15, 222-226. 